\title{
EL RASTRO DEL CADMIO
}

\section{THE WAY OF CADMIUM}

Carlos Gamero Esparza: Universidad Inca Garcilaso de la Vega. carlos.gamero@ozu.es

\section{CURRÍCULUM VITAE}

Reconocido periodista peruano. Licenciado con Diploma de Honor en la Universidad Inca Garcilaso de la Vega.

\section{RESUMEN}

El cadmio es un metal pesado que se encuentra en el aire viciado, en algunos vertidos industriales, incluidas las aguas residuales, en el reciclaje de desechos de PVC y en la incineración de la basura. También se origina en la producción de plomo, zinc, en la quema de combustibles fósiles (petróleo y derivados) y en el empleo de fertilizantes fosfatados y plaguicidas, muy comunes en nuestra agricultura. Es un elemento tóxico para todos los seres vivos.Pero la industria del plástico sigue insistiendo en la inocuidad de sus productos. Aún así, el círculo de las evidencias se cierra cada vez más. Hace poco un grupo de expertos del Ministerio del Medio Ambiente de España advirtió del peligro de hornear o calentar alimentos envasados en frascos de PVC, debido a su contenido de sustancias tóxicas, siendo una de las más peligrosas un metal blanco no ferroso llamado cadmio, un elemento que ha llamado la atención por su poder de asimilación en el organismo, su mortal potencial cancerígeno y por ser causa de terribles anomalías congénitas, como ha quedado demostrado en diversos estudios científicos. 


\title{
PALABRAS CLAVE
}

Cadmio - Metal - Tóxico - Plástico - Seres vivos

\begin{abstract}
Cadmium is a heavy metal found in the stale air in some industrial wastes, including sewage, recycling of PVC waste and waste incineration. It also originates from the production of lead, zinc, in the burning of fossil fuels (oil and derivatives) and in the use of phosphate fertilizers and pesticides, very common in our agriculture. It is a toxic element for all living beings. But the plastics industry continues to emphasize the safety of their products. Even so, the circle of evidence closes more and more. Recently a group of experts from the Ministry of Environment of Spain warned against baking or heating foods packaged in PVC bottles, due to its content of toxic substances, one of the most dangerous non-ferrous white metal called cadmium, a element that has attracted attention for its power of assimilation in the body, its deadly carcinogenic potential and cause terrible birth defects, as has been shown in scientific studies.
\end{abstract}

\section{KEY WORDS}

Cadmium - Metal - Toxic - Plastic - Living Things

\section{ÍNDICE}

1. Introducción

2. La mayoría de envases de PVC se elaboran con cadmio

3. Migración peligrosa 
4. Evítense los recipientes plásticos de colores brillantes para guardar alimentos

5. Plásticos mentirosos

6. Ficha técnica del cadmio

7. ¿Por qué...

8. Alternativas al PVC

9. Téngase en cuenta que...

10. Fuentes

\section{TEXTO:}

El Cadmio es aún más tóxico que el plomo, ya que se le ha relacionado con cáncer y daño a los riñones. (Greenpeace - Australia)

\section{Introducción}

Por negligencia, irresponsabilidad o desconocimiento, muchas industrias plásticas continúan fabricando sus productos de uso masivo utilizando sustancias comprobadamente tóxicas, en especial cadmio. En el Perú, como en otros países de Latinoamérica y tercermundistas, los consumidores desconocen el peligro de calentar indiscriminadamente los alimentos en ciertos envases plásticos dentro de los hornos de microondas. Por ejemplo, no se conocen fabricantes peruanos que adviertan al consumidor sobre la composición y naturaleza de sus plásticos.

Mientras esto sucede, en los países desarrollados ya se tomaron medidas contra el cadmio. Desde 1956 está prohibido en el Reino Unido el uso del cadmio en los utensilios de cocina; en Suecia y Dinamarca se ha prohibido que contengan cadmio 
todos los artículos del hogar. En la UE, desde 1995, está vedado el uso de cadmio en los pigmentos plásticos y plastificantes.

¿Sabía Usted qué?

-En el Laboratorio de Great Plains, en Kansas, el doctor William Shaw y sus colegas han vinculado el cadmio con ciertos síntomas muy parecidos a los del autismo y con algunos trastornos del comportamiento.

-Algunas investigaciones señalan al cadmio como principal causante de una variedad de la enfermedad de los bebés azules (que no es la que conocemos en el Perú como cardiopatía congénita), una anomalía que impide a la sangre oxigenar normalmente el organismo, vinculada con el nitrato de cadmio.

-Debido a que este metal también está presente en el humo de los cigarrillos, los fumadores tienen dos veces más cadmio en su organismo que los no fumadores.

-Los plastificantes conocidos como ftalatos son los contaminantes ambientales más comunes en el planeta, aunque la industria del plástico diga lo contrario. El 95\% de ellos se producen para ser utilizados en la fabricación de PVC flexible.

\section{Diversos informes advierten que el cadmio es absorbido por los cultivos}

El catedrático Nieves y la Organización Mundial de la Alimentación alertan del riesgo para la salud pública

Esta noticia publicada recientemente por un diario español refleja una situación que, como en Europa, también se repite en el Perú, pero nadie lo denuncia. Ya se ha demostrado que el cadmio también puede llegar a nuestro organismo por medio de los alimentos contaminados procedentes del campo. Un informe de la filial peruana de CEPIS/OMS ha revelado la presencia de plomo y cadmio en productos agrícolas, en zonas rurales y mercados de Lima y Callao. Las muestras de cultivos (maíz, papa, espinaca, zanahoria y fresa) se obtuvieron en terrenos regados con aguas contaminadas sin tratar (negras o residuales).

\section{La mayoría de envases de PVC se elaboran con cadmio}

La industria del plástico sigue insistiendo en la inocuidad de sus productos. Aún así, el círculo de las evidencias se cierra cada vez más. Hace poco un grupo de expertos del Ministerio del Medio Ambiente de España advirtió del peligro de hornear o calentar alimentos envasados en frascos de PVC, debido a su contenido de sustancias tóxicas, siendo una de las más peligrosas un metal blanco no ferroso llamado cadmio, un elemento que ha llamado la atención por su poder de asimilación en el organismo, su mortal potencial cancerígeno y por ser causa de terribles anomalías congénitas, como ha quedado demostrado en diversos estudios científicos.

La exposición a este metal en los humanos se produce generalmente por la ingesta de agua y alimentos contaminados y por inhalación. Una exposición continuada puede provocar daños internos irreversibles e incluso la muerte por inhalación. Empero, la industria del plástico lo considera necesario en la fabricación de sus aditivos: cloruro de vinilo sin polimerizar, pigmentos -como el rojo, naranja o amarillo intensos- para colorear diversos utensilios del hogar; además, agentes plastificantes como los 
adipatos y los llamados ftalatos (fthalatos), sustancias químicas que, al igual que los otros aditivos, se desprenden fácilmente del plástico para migrar o pasarse a otras sustancias como ocurre con la comida.

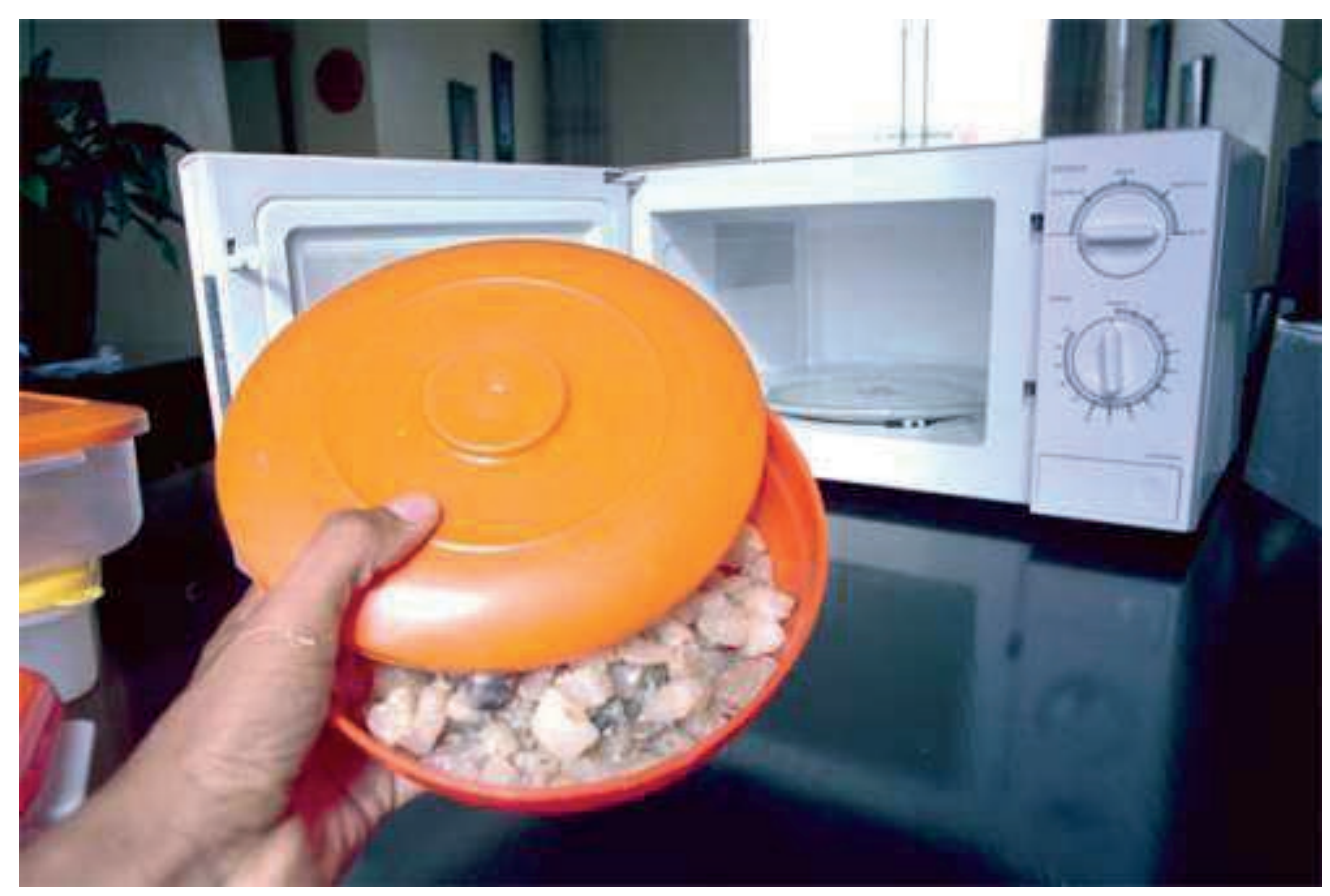

¿Alimento sano en plástico sano? La polémica está servida Fotografía: Max Cabello (Diario OJO, Lima -- Perú)

\section{Migración peligrosa}

Esta situación se agrava cuando el PVC es sometido a cambios bruscos de temperatura o a fuentes de energía electromagnética. En un artículo publicado el año pasado en el Portal español "Canal Salud", María Isabel Cambero y Leonides Fernández, profesores de Tecnología de los Alimentos de la Universidad Complutense de Madrid, explican que, si bien muchos recipientes de plástico se consideran e incluso se etiquetan como aptos para el microondas $y$, aunque éstos generalmente son transparentes a las microondas y dejan que éstas lleguen al alimento, "muchos (envases) no resisten la temperatura que alcanza la comida durante su cocinado en microondas y se desestabilizan, alteran o funden 
parcialmente. En estos casos puede producirse migración de los componentes del envase al alimento (plastificantes, oligómeros del plástico, etc.)".

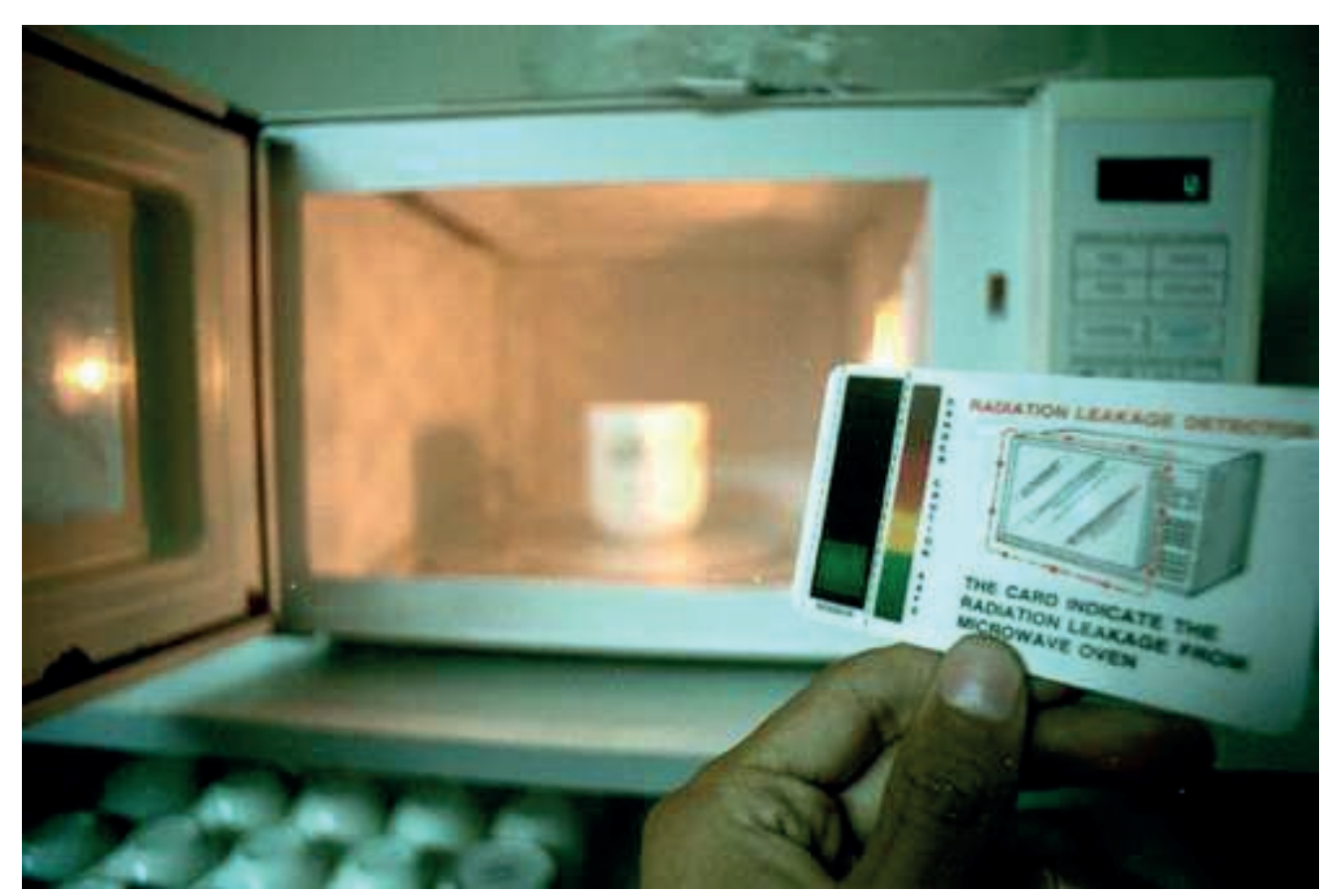

Con esta tarjeta de microondas (microwave card) se puede medir la cantidad de radiación electromagnética que está recibiendo un alimento durante su calentado en un horno microondas. Fotografía: Max Cabello (Diario OJO, Lima -- Perú)

El fenómeno de las migraciones ha sido ampliamente estudiado. El doctor William Shaw, director del laboratorio Great Plains, en Kansas (EEUU), e Investigador de Anormalidades Bioquímicas en el Organismo relacionadas con varios trastornos de la salud, comentaba que el cadmio podía estar presente en recipientes plásticos y también en el papel-plástico diseñado para envolver las comidas prefabricadas y para guardar los alimentos. Al calentar estos alimentos dentro del papel-plástico y en algunos recipientes por medio de un horno microondas, el cadmio puede pasar a la comida y provocar la intoxicación. 


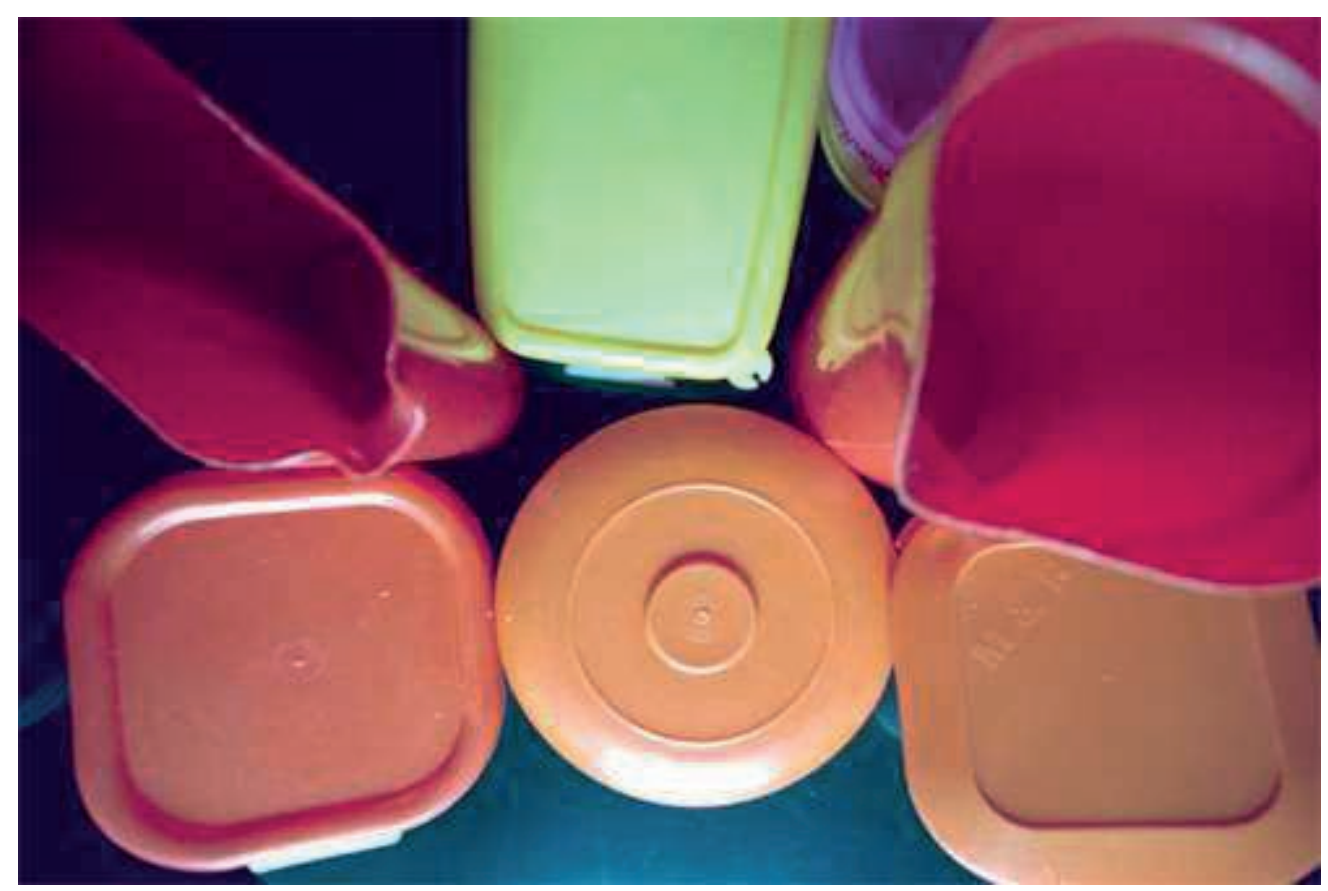

Colores bonitos pero engañosos. Los pigmentos utilizados para colorear estos envases suelen tener cadmio y plomo. Fotografía: Max Cabello (Diario OJO, Lima -Perú)

\section{Evítense los recipientes plásticos de colores brillantes para guardar alimentos}

"Hay que evitar utilizar envases de plástico de colores intensos -amarillo, naranja y rojo- por presumirse que están asociados a pigmentos fabricados a base de cadmio. Esta medida de precaución obedece a una serie de cuestionamientos resultantes de investigaciones que se vienen realizando en países desarrollados, donde se menciona que los plásticos que contendrían cadmio y que se usan para calentar alimentos, agua, etc., en un horno microondas, podrían, al ser los alimentos expuestos a la energía y frecuencia del microondas, forzar a que los compuestos de cadmio (del envase plástico de turno) migren hacia los alimentos", coincide el Ingeniero Manuel Luque Casanave, Gerente de Producción Limpia del Consejo Nacional del Ambiente (CONAM). 


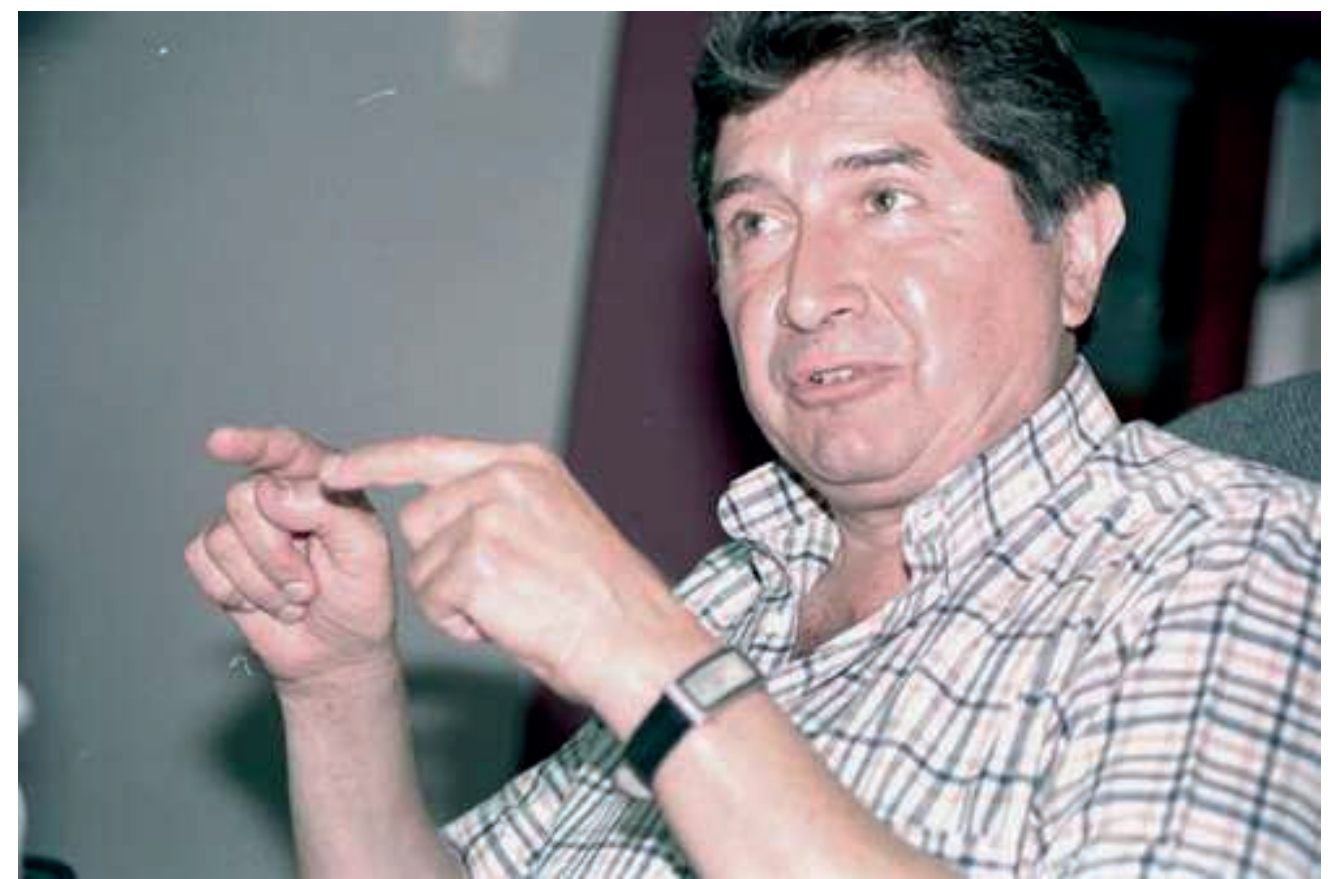

Ingeniero Manuel Luque Casanave, Gerente de Producción Límpia del CONAM, una institución gubernamental peruana dedicada a la investigación de la contaminación ambiental y su impacto en la calidad de vida. Fotografía: Max Cabello (Diario OJO,

$$
\text { Lima -- Perú) }
$$

\section{Plásticos mentirosos}

Los vasos, platos, jarras, botellas y envases de PVC (con cadmio) pueden ser muy bonitos, pero... 




Los colores del cadmio: estos envases son llamativos pero...

Fotografía: Max Cabello (Diario OJO, Lima -- Perú)

Los aditivos no sólo le dan al PVC un aspecto atractivo sino que también pueden pasar al organismo por migración a través del agua y la comida. Una vez adentro, el cadmio se fija a los tejidos y llega al hígado donde se une con la metalotioneína, una pequeña proteína compuesta de alto número de residuos de cisteína. La mayor parte del cadmio absorbido se acumula en el hígado y los riñones, unido a dicha proteína. Cuando estos órganos ya no pueden sintetizar la Metalotioneína sobreviene una nefropatía o deterioro tanto hepático como renal.

Otros órganos sufren igualmente por culpa del cadmio. En el sistema digestivo provoca irritación estomacal, náusea, vómito, diarrea, dolor abdominal y muscular, 
así como salivación excesiva; en los pulmones causa enfisema, bronquitis crónica y cáncer pulmonar; en el sistema circulatorio causa enfermedades del corazón (incluso anomalías congénitas), anemia y presión alta; en el hígado puede causar disfunción y posible cáncer hepático; en el sistema inmune, provoca una disminución en las respuestas inmunológicas del organismo. Pero es en los riñones donde el cadmio hace más daño, provocando cálculos y proteinuria (insuficiencia o merma en la capacidad de filtrar la orina), entre otros males.

Diversos ensayos con animales y seres humanos han encontrado una relación entre el cadmio y casos de cáncer prostático y testicular; un trabajo clínico, publicado en 1998 en el British Medical Journal, mencionó que el carcinoma de vesícula podría estar relacionado con concentraciones de cadmio y plomo en el tracto digestivo. Por otro lado, se ha relacionado este metal con descalcificación y fracturas óseas.

\section{UNA BOTELLA DE PVC (DONDE USTED TOMA SU AGUA MINERAL O SU GASEOSA) CONTIENE CADMIO SI...}

-...no menciona en ningún lugar visible de que material está hecha.

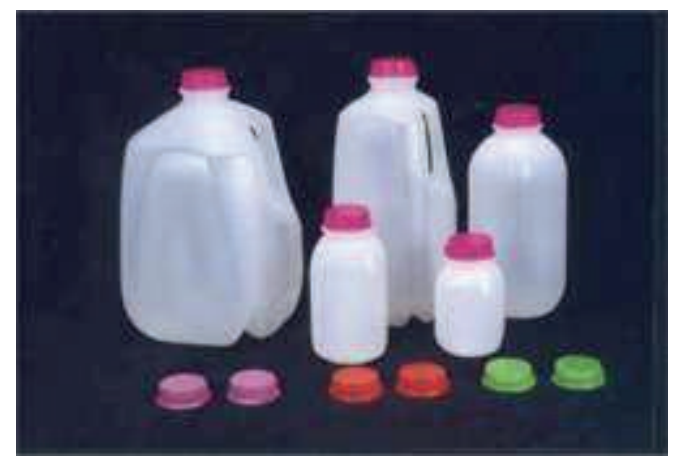

-...tiene un tono azulado. 


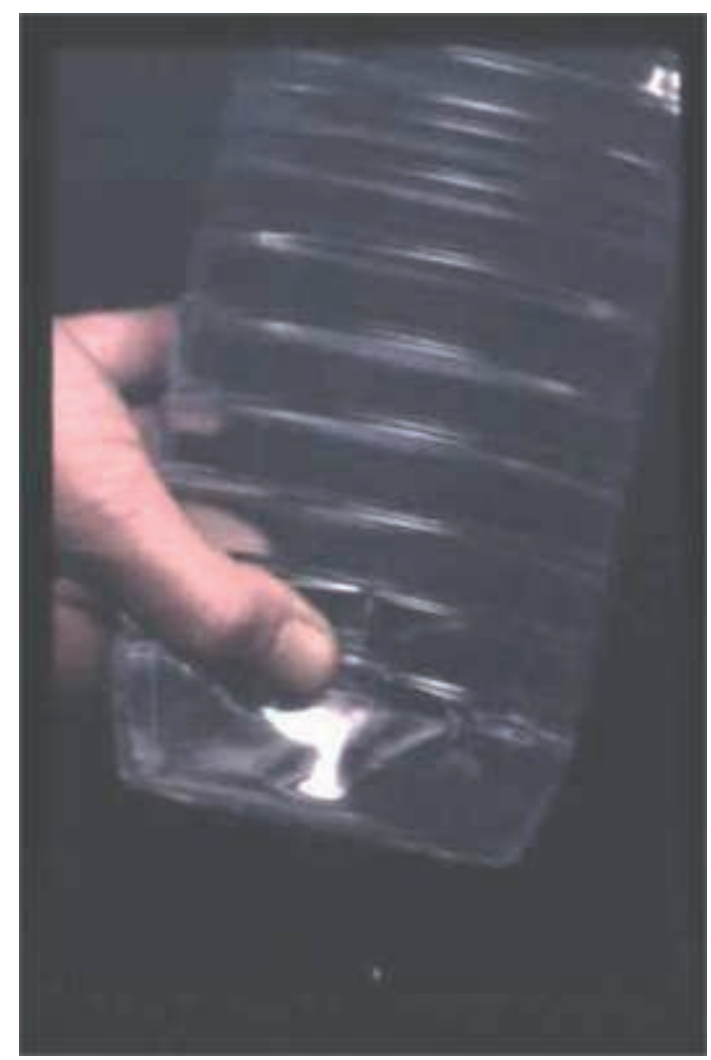

-...cuando se abolla en cualquier zona, aparecen unas manchas blanquecinas en el lugar en que se producen dobleces.

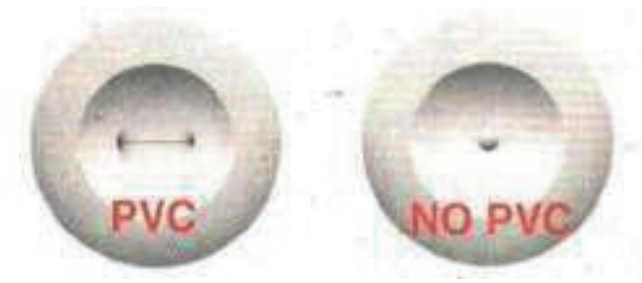

-...en su base presenta una cicatriz lineal en vez de un punto en el centro.

\section{Ficha técnica del cadmio}

Es un metal pesado que se encuentra en el aire viciado, en algunos vertidos industriales, incluidas las aguas residuales, en el reciclaje de desechos de PVC y en la incineración de la basura. También se origina en la producción de plomo, zinc, en la quema de combustibles fósiles (petróleo y derivados) y en el empleo de fertilizantes 
fosfatados y plaguicidas, muy comunes en nuestra agricultura. Es un elemento tóxico para todos los seres vivos.

El cadmio no se encuentra en estado libre en la naturaleza y la Greenokita (sulfuro de cadmio) único mineral de cadmio, no es una fuente comercial de este metal.

Nombre: Cadmio

Símbolo: Cd

Clasificación: Metales no ferrosos.

Valencia: 2 (divalente)

Número Atómico: 48

Número de Protones/Electrones: 48

Peso/masa Atómica: 112,40

Punto de Fusión: $\left({ }^{\circ} \mathrm{C}\right) 321,07$

Punto de Ebullición: $\left({ }^{\circ} \mathrm{C}\right) 767$

Densidad: (Kg/m3): 8650; $\left(20^{\circ} \mathrm{C}\right)$

Volumen Atómico: (cm3/mol): 13,00

Estructura Cristalina: Hexagonal.

Característica: Metal pesado no ferroso.

Color: Blanco-plateado.

Apariencia: Se presenta como un metal suave al tacto.

Vida biológica dentro del organismo: entre 20 y 30 años.

Países Productores de Cadmio: Estados Unidos, Canadá, México, Australia, Bélgica, Luxemburgo, España, República de Corea, Argentina, Bolivia, Chile, Perú son los principales países productores de este metal tóxico. Otros como Rusia, China, Sudáfrica, India y Venezuela también producen cadmio. 


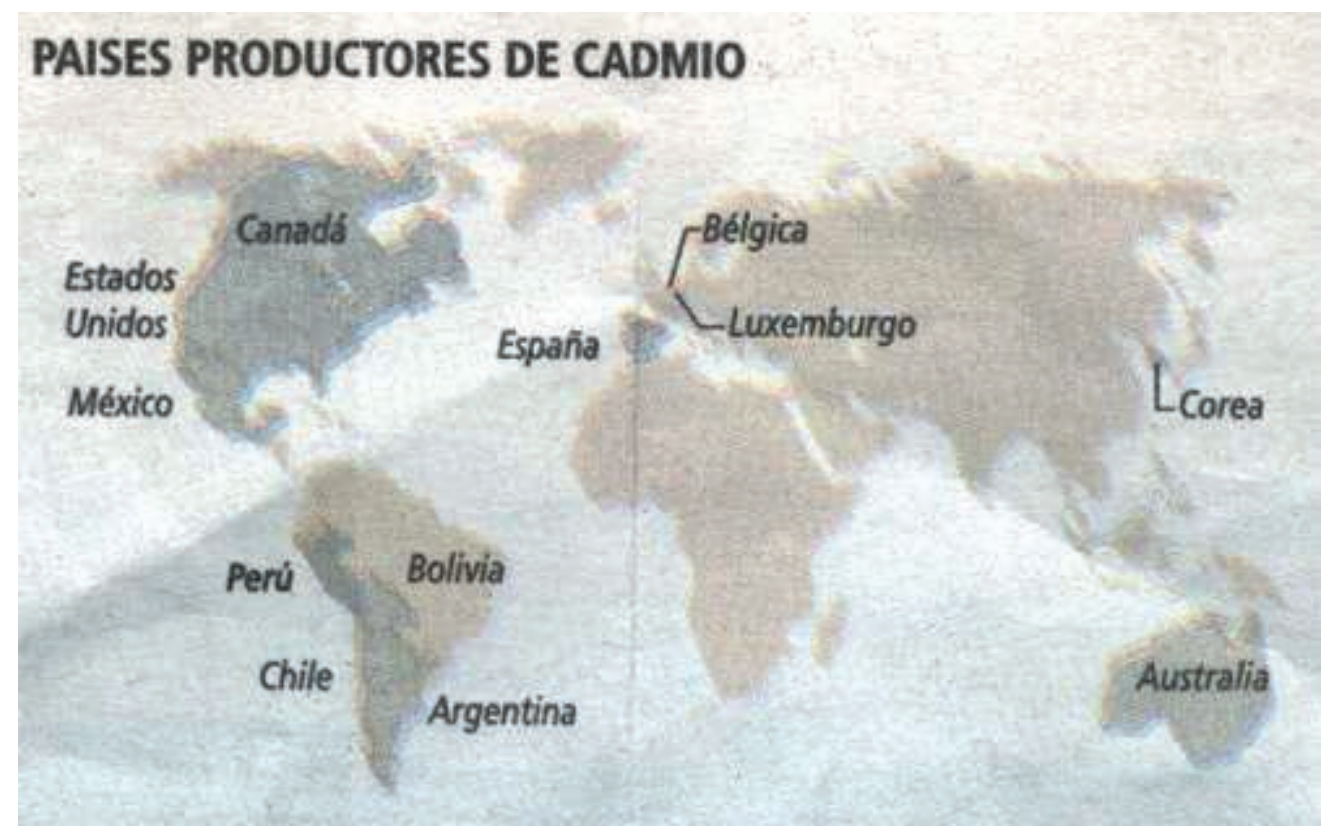

Producción envenenada: el cadmio en el mundo. Imagen obtenida del Diario "OJO", Lima - Perú

Algo de historia: Plinio dio el nombre de "cadmia" a un polvo pardo que se acumulaba en las chimeneas de los hornos de fundición que se empleaban en la fabricación del latón. De este polvo pardo (básicamente carbonato de zinc) aisló Friedrich Stromeyer el cadmio en 1817.

Dato informativo: El cadmio es utilizado desde hace muchos años en la industria automotriz (galvanoplastia) y en la fabricación de baterías.

\section{7. ¿Por qué...}

... después de comprobada su toxicidad, se sigue utilizando cadmio en la fabricación del PVC habiendo alternativas más sanas?

Según Greenpeace, la industria plástica aduce que el PVC requiere plomo y cadmio debido a que es el único plástico que está hecho de cloro. La industria del vinilo podría prometer reemplazar los aditivos tóxicos con sustancias más "seguras", pero 
su historia indica que usualmente un producto químico tóxico que es conocido es reemplazado por otro producto químico tóxico desconocido.



Parte delantera de la tarjeta postal enviada por Greenpeace-España, en la que pide boicotear a las empresas que envasan agua mineral, zumos y leche en botellas de PVC y cuyos nombres aparecen en el dibujo. 




Parte delantera de la tarjeta postal enviada por Greenpeace a los ministros de Medio Ambiente de todo el mundo.

Entonces, lo más seguro para los consumidores es evitar el PVC.

\section{Alternativas al PVC}

Polietileno - (Polyetilene):

Se utiliza para las botellas y las bolsas de supermercado. Debido a su estructura compuesta por carbono e hidrógeno, no lleva aditivos tóxicos.

Polipropileno (PP) - (Polypropylene):

Es utilizado en envases para alimentos. Son de gran resistencia al calor, ya que no se funden por debajo de $\operatorname{los} 160^{\circ} \mathrm{C}$. Es un polímero vinílico y posee una estructura muy similar al Polietileno.

Poliestireno (PET) - (Polyestyrene):

Las tazas plásticas transparentes, algunos platos, vasos y ciertos frascos están hechos de este material parecido al polietileno, aunque lo malo radica en su estructura: es un 
polímero vinílico hidrocarbonado producido por una polimerización vinúlica por radicales libres, unas moléculas que han sido vinculadas al envejecimiento y al desarrollo de numerosos cánceres.

\section{Téngase en cuenta que...}

... hay envases que son fabricados con polietileno y PVC, e incluso una combinación de éstos con polipropileno y poliestireno; algunos frascos considerados aptos para hornos microondas, si bien no tienen PVC, son coloreados con pigmentos tóxicos.

... los envases plásticos más seguros para ser utilizados en hornos microondas suelen ser transparentes -no opacos-, con tapas herméticas transparentes o de color crema claro o blancos.

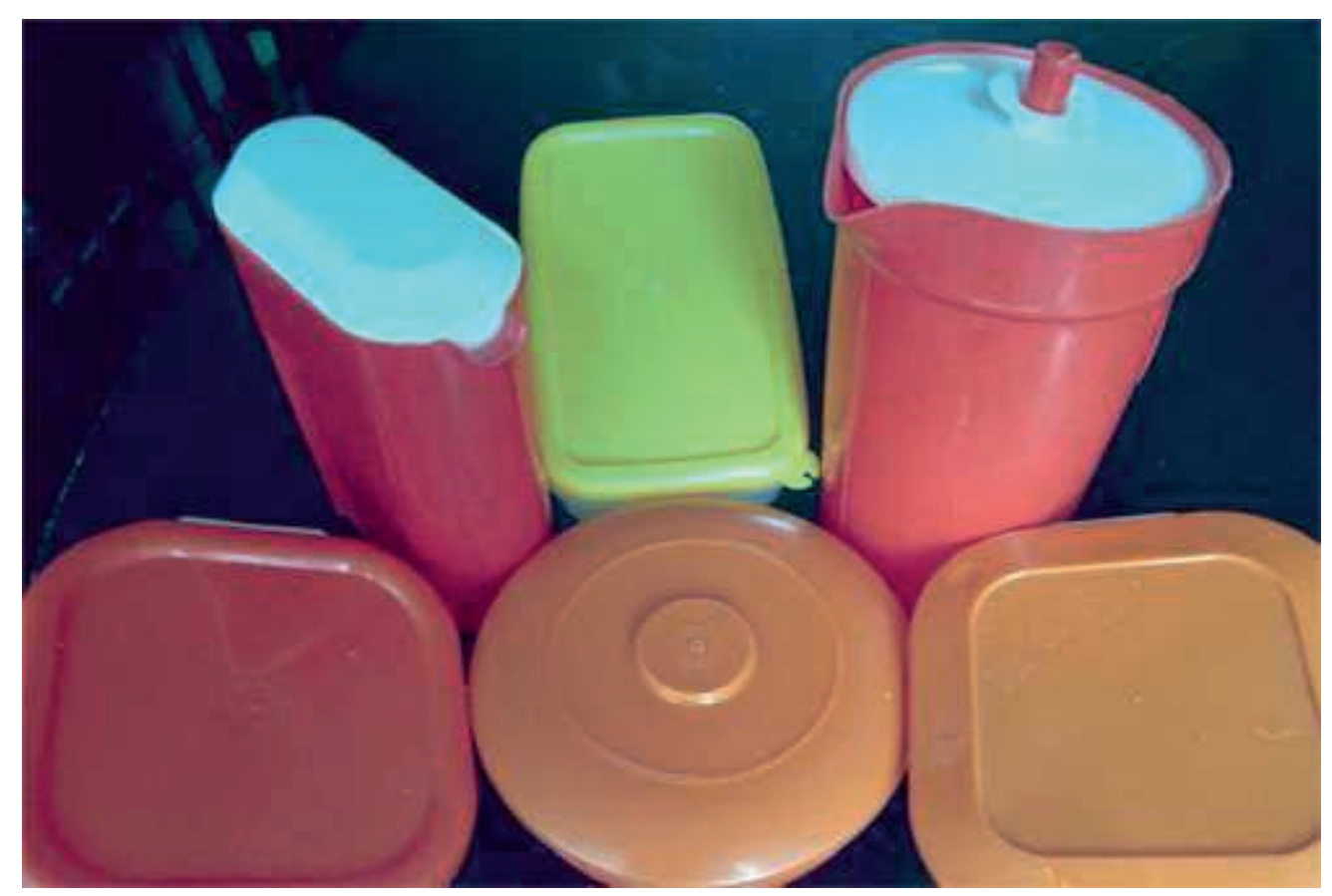

¿Sabe usted diferenciar cuál de estos envases de plástico no tiene cadmio? Fotografía: Max Cabello (Diario OJO, Lima -- Perú)

Ahora, debido a las rigurosas normas sanitarias, en Estados Unidos y Gran Bretaña, muchos frascos para "cookeware" (microondas) importados, suelen llevar una 
etiqueta donde dice: "PVC Free" -Libre de PVC- o "PlaySafe - Buy PVC Free" -Este es un envase seguro, libre de PVC-.


Si usted no encuentra estas etiquetas en los envases que utiliza, puede contar con el beneficio de la duda.

\section{Greenpeace vient de créer un site} en anglais sur les alternatives au PVC : un plastique hautement toxique et porsongensinc cancèrigène.

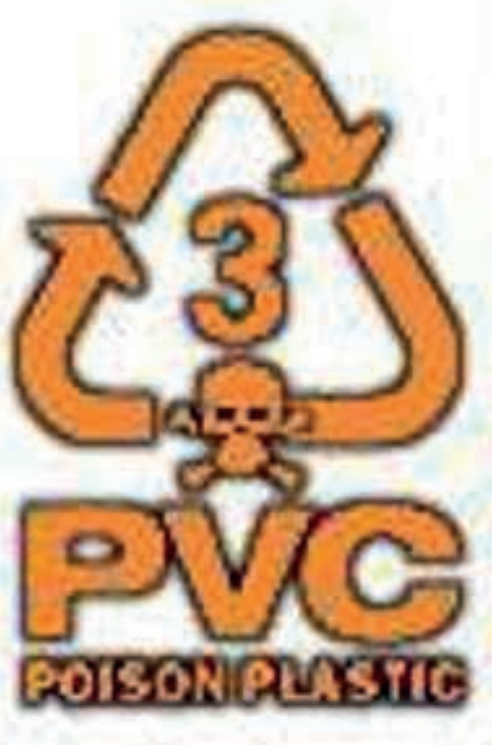

En este anuncio de Greenpeace- Francia se divulga la creación de una página WEB informativa sobre las alternativas del PVC 


\section{Fuentes}

CONAM/Waste Magazine

Laboratorio Great Plains - Kansas (EE.UU.)

Fons de Documentació del Medi Ambient - Valencia (España)

Greenpeace - España

INPPAZ - OPS-OMS

CEPIS - OPS

UDEC - Chile

Pangea Org - España

www.medspain.com

www.canalsalud.com

Emile-Henry/www.psrc.usm.edu 